Mini Review

\title{
A Transgenic Rat Model of Prostate Carcinogenesis
}

\author{
Makoto Asamoto ${ }^{1}$, Naomi Hokaiwado ${ }^{1}$, Young-Man $\mathrm{Cho}^{1}$, and Tomoyuki Shirai ${ }^{1}$ \\ ${ }^{1}$ Department of Experimental Pathology and Tumor Biology, Nagoya City University Graduate School of Medical \\ Sciences, Nagoya 467-8601, Japan
}

\begin{abstract}
We have generated a transgenic rat with the SV40 T antigen under probasin promoter control, allowing prostate specific gene expression. Males demonstrate atypical epithelial cell proliferation in the prostate from 4 weeks of age and develop prostate carcinomas at $100 \%$ incidence before they are 15 weeks old. These prostate caricnomas are completely androgen-dependent. Adequate materials of the prostate carcinomas, taking advantage of the rat transgenic model, allow us gene expression analysis for prostate carcinogenesis and involution process after castration. Male transgenic rats with a Sprague-Dawley genetic background were mated with wild-type females of F344, Wistar and ACI strains. F1 male transgenic hybrids with female Wistar and ACI rats had significantly lowered incidences of prostate carcinomas. However, the serum level of testosterone, and expression of the transgene, probasin, and the androgen receptor did not correlate with the strain variation in tumor development. These results clearly show that the transgenic rat is a good model for investigate prostate carcinogenesis and its modifying factors.

(Toxicol Pathol 2002; 15: 191-196)
\end{abstract}

Key words: transgenic rats, prostate, adenocarcinoma, castration, strain difference

\section{Introduction}

Prostate cancer, the most common malignant disease in the Western world, has increased dramatically over the past decade. In the United States, it ranks second only to lung cancer as a cause of cancer related deaths ${ }^{1}$. Despite this serious situation, the basic biology, etiology and risk factors for prostate cancer remain largely to be elucidated. Several mouse transgenic models have already been established ${ }^{2}$, which may contribute to analyze molecular, cellular and physiological events in prostate carcinogenesis. However, rats have advantages for this purpose $\mathrm{e}^{3,4}$, their larger size, for example, allowing adequate materials to be obtained. Furthermore, several rat prostate models using chemical carcinogens have been established ${ }^{5,6}$, and data for hormone effects and modifying agents have accumulated ${ }^{7-16}$. The problem is that these models are labor intensive and require long periods to induce tumors, which are usually microscopic and not suitable for molecular biological analysis. Therefore, we have established a rat transgenic prostate cancer model using the probasin gene promoter and the SV40 T antigen gene. The rat probasin gene encodes an

Received: 30 June 2002, Accepted: 17 August 2002

Mailing address: Makoto Asamoto, Department of Experimental

Pathology and Tumor Biology, Nagoya City University Graduate

School of Medical Sciences, 1Kawasumi, Mizuho-cho, Mizuho-ku,

Nagoya 467-8601, Japan

TEL: 81-52-853-8156 FAX: 81-52-842-0817

E-mail: masamoto@med.nagoya-cu.ac.jp androgen- and zinc-regulated protein specific to the dorsolateral epithelium of the prostate ${ }^{17}$. Cis-acting androgen-response regions within the 5' flanking region have been identified ${ }^{18}$ and recently, the ability of the prostate-specific rat probasin gene promoter to target heterologous genes specifically in the prostate of transgenic mice was demonstrated ${ }^{19,20}$. In rats also, the gene promoter would be expected to work in the same way because this was the species from which it was originally isolated ${ }^{17}$. The Simian virus 40 (SV40) early-region tumor antigen has the ability to induce transformation in vivo ${ }^{21}$, the SV40 large tumor $\mathrm{T}$ antigen (Tag) acting as an oncoprotein through interactions with retinoblastoma ${ }^{22}$ and p53 tumor-suppressor gene products ${ }^{23,24}$ while the small $\mathrm{t}$ antigen interacts with protein phosphatase $2 \mathrm{~A}^{25}$. SV40 Tag in particular has been used successfully in transgenic mice to induce tumors in a variety of organs, including the prostate ${ }^{20,26,27}$. It also proved useful in the liver of transgenic rats ${ }^{28}$.

Probasin-SV40 T antigen transgenic rats were here generated by microinjection of recombinant DNA of the probasin gene promoter, fused to the SV $40 \mathrm{~T}$ antigen, into pronuclei of Sprague-Dawley rat embryos.

\section{Androgen-Dependency of the Prostate Carcinomas in the Probasin-SV40 T Antigen Transgenic Rats}

\section{Experiment 1}

A total of 25 transgenic male rats were divided into 5 groups. In group 1, 5 rats were maintained until 25 weeks 
Table 1. Effects of Genetic Background on Prostate Carcinogenesis of PB/SV40Tag Transgenic Rats

\begin{tabular}{cccccc}
\hline & & \multicolumn{4}{c}{ Number of rats with (\%) } \\
\cline { 3 - 5 } Genetic background & No. of rats & I & II & III & Adenocarcinoma \\
\cline { 3 - 5 } SD & 10 & 0 & 0 & $2(20)$ & $8(80)$ \\
SD $\times$ Wistara & 5 & 0 & $1(20)$ & $4(80)$ & 0 \\
SD $\times$ F344 & 6 & 0 & 0 & $1(16.7)$ & $5(83.3)$ \\
SD $\times$ ACI & 6 & 0 & 0 & $5(83.3)$ & $1(16.7)$ \\
\hline
\end{tabular}

PIN: prostate intraepithelial neoplasia. Grading defined with glandular structure. I: slight papillary proliferations, or similar to normal glands. II: moderate papillary prolfierations. III: severe papillary proliferations, occasional luminal bridging, a: Significantly different from the SD strain by Scheffe's analysis at $\mathrm{P}=0.0028$.

old, and killed. In group 2, 5 rats were castrated at 20 weeks of age, and kept until 25 weeks old when they were killed. In group 3, 5 rats were castrated at 5 weeks of age, and kept until 25 weeks. In groups 4 and $5,1.5 \mathrm{~cm}$ long Silastic tubes containing $30 \mathrm{mg}$ testosterone propionate (Sigma Chemical Co., St. Louis, MO, USA) were implanted into the subcutis of the dorsal region of 5 animals each at 5 weeks old of age, which were then killed when 25 weeks old. In group 5, castration and removal of the testosterone tubes were performed at 20 weeks of age.

In experiment 1 , effects of administration of testosterone propionate and castration on prostate carcinogenesis were investigated in probasin-SV40 Tag transgenic rats. Macroscopically, prostates of the transgenic rats in the non-treated group (group 1) showed slight enlargement and irregular surfaces, but no apparent nodule or mass formations. Castration at 20 weeks of age (group 2) caused severe atrophy in both the prostate and the seminal vesicles. Testosterone propionate treatment, in contrast, caused enlargement, especially in the anterior lobes and seminal vesicles. Surfaces of these prostates were irregular, and in anterior lobes hemorrhage was frequently observed. Castration after testosterone propionate treatment induced prostate and seminal vesicle atrophy. Weights of prostates and seminal vesicles with urinary bladders were measured. Treatment with testosterone propionate (Group 4) caused increase, while castration (Groups 2, 3 and 5) resulted in dramatic decrease.

In the non-treatment group (group 1), the transgenic rats developed prostatic intraepithelial neoplasias (PIN) and adenocarcinomas in the ventral, dorso-lateral and anterior prostates at very high incidences. Almost all glands consisted of atypical cells, diagnosed as PIN or adenocarcinomas (Fig. 1). This may be a reason that the prostate of the transgenic rats looks enlarged, but without obvious formation of masses or nodules. Castration at 20 weeks of age (group 2) caused involution completely after 5 weeks, when no neoplastic lesions were found, and only atrophic glands without atypia and fibrosis were observed (Fig. 2). Castration at 5 weeks of age (group 3) suppressed tumor development completely. In this group, atrophic

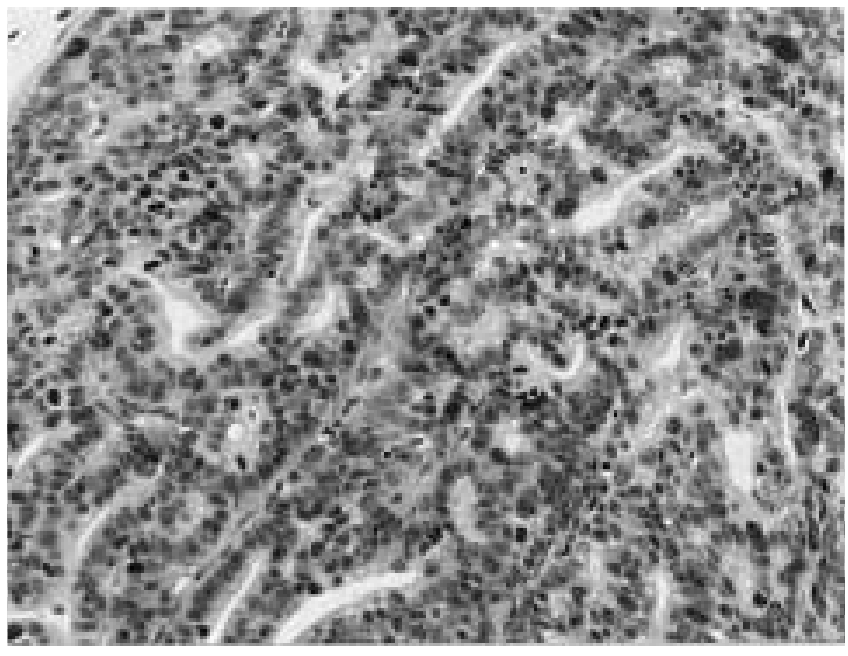

Fig.1. An adenocarcinoma of the ventral lobe in the probasin-SV40 Tag transgenic rat. H\&E, $\times 200$.

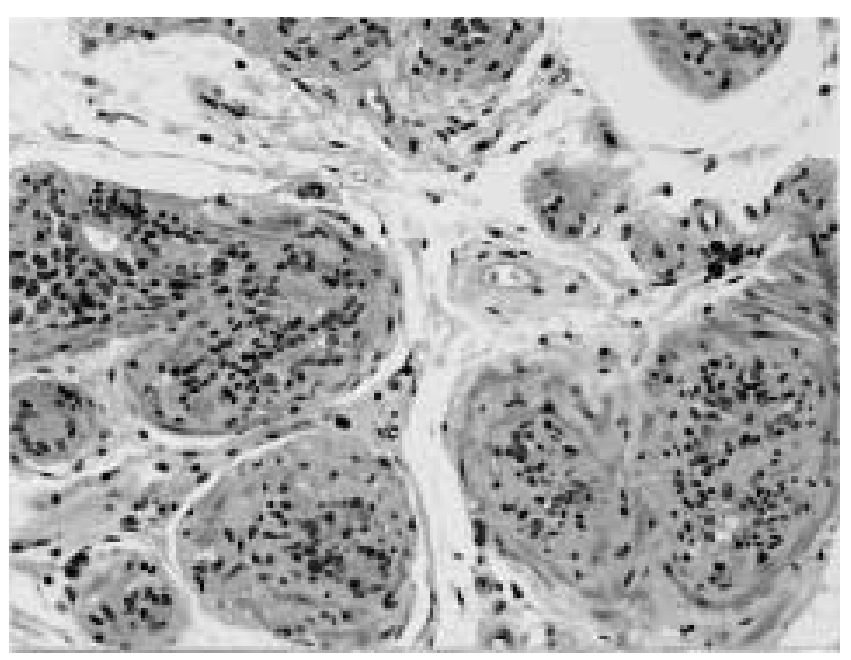

Fig. 2. Atrophic glands in the prostate of the probasin-SV40 Tag transgenic rat after castration. H\&E, $\times 200$. 
glands without atypia surrounded by slight fibrosis were found. Testosterone propionate treatment enhanced atypical cell proliferation with formation of solid adenocarcinomas featuring cribriform patterns. Micro-invasion was often observed in this group, but, no metastases were noted. Even after enhancement of cell proliferation by testosterone, castration caused complete involution, leaving only atrophic glands without atypia and severe fibrosis and no neoplastic lesions retained in group 5 at week 25 .

\section{Experiment 2}

In a total of 21 transgenic male rats, $1.5 \mathrm{~cm}$ long Silastic tubes containing $30 \mathrm{mg}$ testosterone propionate were implanted at 5 weeks of age. Castration and removal of the testosterone tubes were performed at 15 weeks of age and rats were killed $0,1,2,3,7,14$, and 21 days thereafter.

In experiment 2 , involution of the adenocarcinomas with enhanced cell proliferation due to testosterone propionate was induced by castration. One to three days after castration, numerous apoptotic bodies were observed and inflammatory cells including neutrophils, lymphocytes and foamy cells had infiltrated the lesions. After seven days, atrophic glands and fibrosis were frequently observed, and nuclear atypia of the glands were minimal. Therefore, these lesions could no longer be diagnosed as carcinomas. Degree of atrophy of the glands and fibrosis were increased 14 and 21 days after castration. SV40 Tag expression was detected immunohistochemically in almost all cells of the prostate adenocarcinomas until 2 days after castration, but at day 3, only a small proportion showed positive reactions. After 7 days, almost no expression of the transgene was detected. Expression of androgen receptors was dramatically diminished from just 1 day after castration, and no positive signals were detected after day 2 immunohistochemically.

Using the prostate materials obtained in experiment 2 , expression of caspase 3, caspase 6, bcl-x and $B A X$, as apoptosis-related genes, was investigated by quantitative RT-PCR, in addition to TRPM-2 and MMP7. Expression of caspase 3 and 6 in carcinomas before castration was higher than that in normal prostate tissue, and increased to a peak 2 days after castration. Expression of $b c l-x$ and $B A X$ was also increased, but the peaks were at day 7. TRPM-2 and MMP7 expression also increased with peaks at day 3. Changes in TRPM-2 were furthermore confirmed by western blotting.

\section{Effects of Genetic Background on Prostate Carcinogenesis}

The age-adjusted incidence of prostate carcinomas in African-American men is approximately $50 \%$ greater than in white men ${ }^{29}$. The associated death is also higher after adjustment for age and stage ${ }^{30}$ and epidemiological observations have led to the hypothesis that prostate carcinoma in African-American men is more biologically aggressive than in white men, due to genetic differences ${ }^{31,32}$. Subtypes of the disease are linked to familial clustering and there is also a hereditary form, supporting the conclusion that genetic events may be involved in prostate cancer pathogenesis $^{33,34}$.

For the present experiment, heterologous transgenic males with the Sprague-Dawley (SD) rats background were mated with wild type female F344, ACI, and Wistar rats (Clea), and F1 male transgenic rats were obtained with SD plus F344, ACI and Wistar as the genetic haplotype background. These were maintained until 15 weeks of age, and killed. Prostates were removed and weighed and half of each ventral lobe was immediately frozen in liquid nitrogen for RNA extraction. The remainder of the prostate was fixed in $10 \%$ buffered formalin for histological examination, then routinely processed for embedding in paraffin. Neoplastic lesions of the prostate were classified as prostatic intraepithelial neoplasia (PIN) and adenocarcinoma. PIN lesions were divided into 3 grades according to the glandular structure; I, similar to normal glands or slightly papillary; II, moderate papillary proliferation; III, severe papillary proliferation with occasional luminal bridging. The tongues of the transgenic rats were also removed and slices taken through the papilla circumvallata for examination of tumor cells in the taste buds. Five $\mu \mathrm{m}$ thick sections were cut and stained with H\&E. The tongue tumors were divided into four stages, histologically: pTis, tumor cells within taste buds or epithelium, with no invasion of stroma; pT1, tumor cells invading the stroma but not the muscle layer; pT2, tumor cells penetrating up to upper half the muscle layer; pT3, tumor cells invading through the upper half of the muscle layer.

Histological examination of the ventral prostate revealed the original transgenic rats having a pure SD background to develop adenocarcinomas at high incidence $(80 \%)$, whereas F1 transgenic rats with a Wistar background demonstrated only prostate intraepithelial neoplasia (PIN), and did not have apparent carcinomas. In the ACI case, the frequency of prostate cancer was also lower, while the F344 genetic background did not affect transgenic prostate carcinogenesis (Table 1). Absolute and relative prostate weights did not correlate with the incidence of prostate carcinomas. Furthermore, testosterone levels in serum demonstrated no link. Expression of SV 40 Tag, probasin and androgen receptors was highest in animals with a Wistar, F344, and ACI haplotype genetic background, respectively, and none of these parameters correlated with the carcinoma incidence. Immunohistochemical analysis revealed that almost all of the prostate tumor cells expressed both SV 40 Tag and androgen-receptors and these were localized in nuclei of the cells. There was no apparent difference in the staining intensity between the prostate tumor cells in animals of different genetic background.

\section{Discussion}

Elucidation of the pathogenetic basis of prostate carcinogenesis can be facilitated greatly by laboratory models of the disease. We have developed a rat transgenic model producing well-differentiated prostate 
adenocarcinomas in all animals and in a short period using SV40 Tag under control of the probasin gene promoter. A transgenic mouse model of prostate carcinomas (TRAMP) using the same gene construct was earlier established by Greenberg et al. ${ }^{20}$, this featuring high grade prostatic intraepithelial neoplasia (PIN) and/or well-differentiated adenocarcinomas of the prostate by 10-12 weeks of age, with spontaneous development of invasive primary tumors that frequently metastasize to the lymph nodes and lungs in 30-36 week old animals ${ }^{20}$. Castration at 12 weeks of age did not inhibit progression to poorly differentiated and metastatic prostate carcinomas in TRAMP mice ${ }^{35}$. Earlier castration at 4 weeks of age reduced prostate cancer development, but some of the mice suffered from androgenindependent prostate carcinomas ${ }^{36}$. In our transgenic rats having the same transgene construct, well-differentiated adenocarcinomas similarly develop in the prostate. However, castration at 20 weeks of age caused complete regression or involution of these carcinomas and earlier castration at 5 weeks of age completely inhibited prostate carcinoma development, in clear contrast to the TRAMP case. Rapid decrease of expression of SV40 Tag and androgen-receptor in the prostate carcinomas after castration is in line with complete androgen-dependence. Because of this complete regression of the lesions and the macroscopic appearance of the prostates with no apparent masses or nodules, the lesion might be suspected of being hyperplastic in nature. However, histological characteristics such as structural and nuclear atypia and micro-invasion are in line with a malignant neoplastic phenotype. Furthermore, the prostate lesions proved tumorigenic in nude mice (data not shown) without any pretreatment such as testosterone injection or Matrigel $^{37,38}$, giving rise to adenocarcinomas similar to the original prostate lesions (Fig. 3). Therefore, the data suggest that the prostate lesions in the transgenic rats are true malignancies (adenocarcinomas).

In our transgenic rat model of prostate carcinogenesis, the developed carcinomas are completely androgen dependent and castration causes complete regression in contrast to the compatible mice model. This has advantages for investigation of involution processes including apoptosis at the tissue level. Histologically, inflammatory cell infiltration was found to be involved in the present case. Increased expression of caspases 3 and 6 , and $B A X$ may reflect apoptotic activity and increased bcl-x may be due to other cells escaping from apoptosis ${ }^{39}$.

Strain differences in cancer susceptibility have been investigated in several organs and used for linkage analysis to identify responsive loci and genes. Regarding prostate carcinogenesis, we previously investigated susceptibility to 3,2'-dimethyl-4-aminobiphenyl (DMAB) in five different rat strains in our laboratory ${ }^{40}$. Carcinomas were respectively found in 46, 50, 5, 0, and 0\% of F344, ACI, Lewis, CD and Wistar strain animals treated with DMAB. The tumor yield correlated well with DMBA-DNA adduct formation except in the Wistar rat case, indicating some linkage between

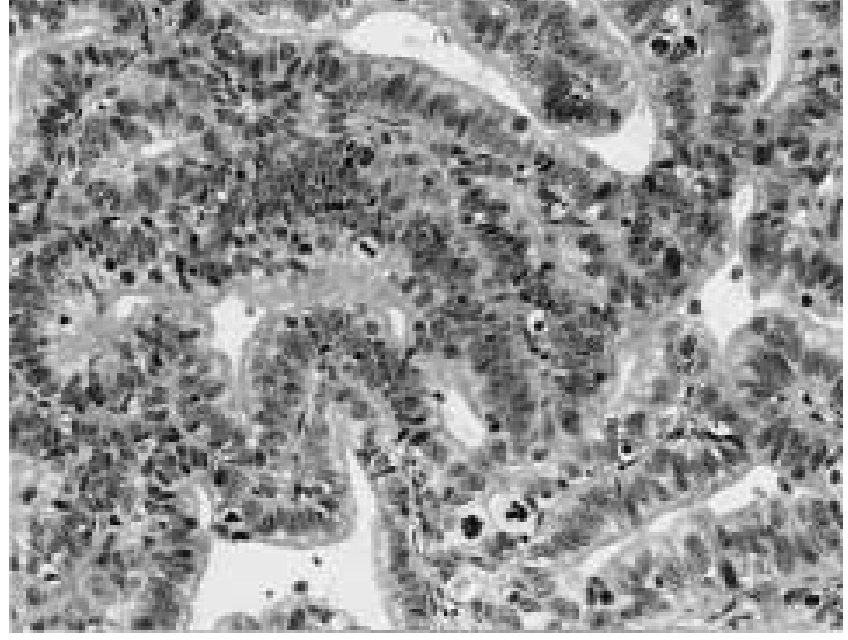

Fig. 3. An adenocarcinoma of the prostate transplanted in a nude mouse. H\&E, $\times 200$.

susceptibility and metabolism of $\mathrm{DMAB}^{40}$. This is not likely to be of direct importance for the present case, however, the transgenic rats developing androgen-dependent prostate carcinomas at very high incidence within a short period (within 15 weeks old) ${ }^{41}$. With chemical carcinogen induction of prostate cancer in animal models malignant lesions usually take over one year to develop. In the present study, F1 hybrids with Wistar transgenic rats did not demonstrate prostate carcinomas, and F1 hybrids with SD and ACI had only small numbers, although both hybrids had PIN III at high incidence ${ }^{42}$. Variation in testosterone levels and expression of the transgene, probasin, and androgenreceptors did not explain the results. Immunohistochemical analysis furthermore showed nuclear expression of the transgene and androgen-receptors to be uniform in prostate tumor cells in all cases, suggesting that both Wistar and ACI strains feature suppressive genetic factors for progression to prostate carcinomas from high grade PIN. In fact, the resistance of Wistar rats to DMAB-induced prostate carcinogenesis, could not be explained simply in terms of carcinogen-adducts ${ }^{40}$. While the prostate tumors are androgen-dependent and the serum testosterone levels of SD $\times$ F344 rats were found to be considerably lower than those in the SD strain, the incidences of adenocarcinomas did not vary, again suggesting independent genetic factors.

In summary, we have developed a transgenic rat model featuring prostate carcinomas that are completely androgendependent. This model may be useful to investigate mechanisms of development of androgen-dependent prostate carcinomas and processes of involution, to evaluate strategies for prevention and treatment, including gene therapy, and to investigate genetic factors. It should be remembered in this context that most human prostate cancers are androgen-responsive before androgen ablation treatments. 


\section{References}

1. Landis SH, Murray T, Bolden S, and Wingo PA. Cancer statistics, 1999. CA Cancer J Clin 1999; 49: 8-31.

2. Sharma P and Schreiber-Agus N. Mouse models of prostate cancer. Oncogene 1999; 18: 5349-5355.

3. Asamoto M, Ochiya T, Toriyama-Baba H, Ota T, Sekiya T, Terada M, and Tsuda $\mathrm{H}$. Transgenic rats carrying human cHa-ras proto-oncogenes are highly susceptible to N-methyl$\mathrm{N}$-nitrosourea mammary carcinogenesis. Carcinogenesis 2000; 21: 243-249.

4. Morimura S, Suzuki T, Hochi S, Yuki A, Nomura K, Kitagawa T, Nagatsu I, Imagawa M, and Muramatsu M. Trans-activation of glutathione transferase $\mathrm{P}$ gene during chemical hepatocarcinogenesis of the rat. Proc Natl Acad Sci USA 1993; 90: 2065-2068.

5. Lucia MS, Bostwick DG, Bosland M, Cockett ATK, Knapp DW, Leav I, Pollard M, Rinker-Schaeffer C, Shirai T, and Watkins BA. Workgroup I: Rodent models of prostate cancer. Prostate 1998; 36: 49-55.

6. Shirai T, Takahashi S, Cui L, Futakuchi M, Kato K, Tamano $\mathrm{S}$, and Imaida K. Experimental prostate carcinogenesisrodent models. Mutat Res 2000; 462: 219-226.

7. Bosland MC. Use of animal models in defining efficacy of chemoprevention agents against prostate cancer. Eur Urol 1999; 35: 459-463.

8. Cui L, Mori T, Takahashi S, Imaida K, Akagi K, Yada H, Yaono M, and Shirai T. Slight promotion effects of intermittent administration of testosterone propionate and/or diethylstilbestrol on 3,2'-dimethyl-4-aminobiphenylinitiated rat prostate carcinogenesis. Cancer Lett 1998; 122: 195-199.

9. Kawabe M, Shibata MA, Sano M, Takesada Y, Tamano S, Ito N, and Shirai T. Decrease of prostaglandin E2 and 5bromo-2'-deoxyuridine labeling but not prostate tumor development by indomethacin treatment of rats given 3,2'dimethyl-4-aminobiphenyl and testosterone propionate. Jpn J Cancer Res 1997; 88: 350-355.

10. McCormick DL, Rao KV, Steele VE, Lubet RA, Kelloff GJ, and Bosland MC. Chemoprevention of rat prostate carcinogenesis by 9-cis-retinoic acid. Cancer Res 1999; 59: 521-524.

11. Miyata E, Kawabe M, Sano M, Takesada Y, Takahashi S, and Shirai T. Effects of tamoxifen, an antiestrogen, on rat prostate carcinogenesis by 3,2'-dimethyl-4-aminobiphenyl and testosterone do not support an estrogen role in testosterone promotion. Prostate 1997; 31: 9-13.

12. Shirai $\mathrm{T}$, Iwasaki $\mathrm{S}$, Masui $\mathrm{T}$, Mori $\mathrm{T}$, Kato $\mathrm{T}$, and Ito N.Enhancing effect of cadmium on rat ventral prostate carcinogenesis induced by 3,2'-dimethyl-4-aminobiphenyl. Jpn J Cancer Res 1993; 84: 1023-1030.

13. Shirai $\mathrm{T}$, Imaida $\mathrm{K}$, Masui $\mathrm{T}$, Iwasaki $\mathrm{S}$, Mori $\mathrm{T}$, Kato $\mathrm{T}$, and Ito N. Effects of testosterone, dihydrotestosterone and estrogen on 3,2'-dimethyl-4-aminobiphenyl-induced rat prostate carcinogenesis. Int J Cancer 1994; 57: 224-228.

14. Shirai T, Sano M, Imaida K, Takahashi S, Mori T, and Ito N.Duration dependent induction of invasive prostatic carcinomas with pharmacological dose of testosterone propionate in rats pretreated with 3,2'-dimethyl-4aminobiphenyl and development of androgen-independent carcinomas after castration. Cancer Lett 1994; 83: 11-116.

15. Shirai T, Tamano S, Sano M, Imaida K, Hagiwara A,
Futakuchi M, Takahashi S, and Hirose M. Site-specific effects of testosterone propionate on the prostate of rat pretreated with 3,2'-dimethyl-4-aminobiphenyl: Dosedependent induction of invasive carcinomas. Jpn J Cancer Res. 1995; 86: 645-648.

16. Tsukamoto $\mathrm{S}$, Akaza $\mathrm{H}$, Onozawa $\mathrm{M}$, Shirai T, and Ideyama Y. A five-alpha reductase inhibitor or an antiandrogen prevents the progression of microscopic prostate carcinoma to macroscopic carcinoma in rats. Cancer 1998; 82: 531-537.

17. Dodd JG, Sheppard PC, and Matusik RJ. Characterization and cloning of rat dorsal prostate mRNAs. Androgen regulation of two closely related abundant mRNAs. J Biol Chem 1983; 258: 10731-10737.

18. Rennie PS, Bruchovsky N, Leco KJ, Sheppard PC, McQueen SA, Cheng H, Snoek R, Hamel A, Bock ME, MacDonald BS, and et al. Characterization of two cis-acting DNA elements involved in the androgen regulation of the probasin gene. Mol Endocrinol 1993; 7: 23-36.

19. Greenberg NM, DeMayo FJ, Sheppard PC, Barrios R, Lebovitz R, Finegold M, Angelopoulou R, Dodd JG, Duckworth ML, Rosen JM, and Matusik RJ. The rat probasin gene promoter directs hormonally and developmentally regulated expression of a heterologous gene specifically to the prostate in transgenic mice. Mol Endocrinol 1994; 8: 230-239.

20. Greenberg NM, DeMayo F, Finegold MJ, Medina D, Tilley WD, Aspinall JO, Cunha GR, Donjacour AA, Matusik RJ, and Rosen JM. Prostate cancer in a transgenic mouse. Proc Natl Acad Sci USA 1995; 92: 3439-3443.

21. Brinster RL, Chen HY, Messing A, van Dyke T, Levine AJ, and Palmiter RD. Transgenic mice harboring SV40 Tantigen genes develop characteristic brain tumors. Cell 1984; 37: 367-379.

22. DeCaprio JA, Ludlow JW, Figge J, Shew JY, Huang CM, Lee WH, Marsilio E, Paucha E, and Livingston DM. SV40 large tumor antigen forms a specific complex with the product of the retinoblastoma susceptibility gene. Cell 1988; 54: $275-283$.

23. Lane DP and Crawford LV. T antigen is bound to a host protein in SV40-transformed cells. Nature 1979; 278: 261263.

24. Linzer DI and Levine AJ. Characterization of a $54 \mathrm{~K}$ dalton cellular SV40 tumor antigen present in SV40-transformed cells and uninfected embryonal carcinoma cells. Cell 1979; 17: 43-52.

25. Pallas DC, Shahrik LK, Martin BL, Jaspers S, Miller TB, Brautigan DL, and Roberts TM. Polyoma small and middle $\mathrm{T}$ antigens and SV40 small $\mathrm{t}$ antigen form stable complexes with protein phosphatase 2A. Cell 1990; 60: 167-176.

26. Adams JM and Cory S. Transgenic models of tumor development. Science 1991; 254: 1161-1167.

27. Shibata MA, Ward JM, Devor DE, Liu ML, and Green JE. Progression of prostatic intraepithelial neoplasia to invasive carcinoma in C3(1)/SV40 large $\mathrm{T}$ antigen transgenic mice: histopathological and molecular biological alterations. Cancer Res 1996; 56: 4894-4903.

28. Hully JR, Su Y, Lohse JK, Griep AE, Sattler CA, Haas MJ, Dragan Y, Peterson J, Neveu M, and Pitot HC. Transgenic hepatocarcinogenesis in the rat. Am J Pathol 1994; 145: 386-397.

29. Parker SL, Davis KJ, Wingo PA, Ries LA, and Heath CW Jr. Cancer statistics by race and ethnicity. CA Cancer J Clin 
1998; 48: 31-48.

30. Robbins AS, Whittemore AS, and Van Den Eeden SK. Race, prostate cancer survival, and membership in a large health maintenance organization. J Natl Cancer Inst 1998; 90: 986990.

31. Cooney KA. Hereditary prostate cancer in AfricanAmerican families. Semin Urol Oncol 1998; 16: 202-206.

32. Kalapurakal JA, Jacob AN, Kim PY, Najjar DD, Hsieh YC, Ginsberg P, Daskal I, Asbell SO, and Kandpal RP. Racial differences in prostate cancer related to loss of heterozygosity on chromosome 8p12-23. Int J Radiat Oncol Biol Phys 1999; 45: 835-840.

33. Ekman P. Genetic and environmental factors in prostate cancer genesis: identifying high-risk cohorts. Eur Urol 1999; 35: $362-369$.

34. Narod S. Genetic epidemiology of prostate cancer. Biochim Biophys Acta 1999; 1423: F1-13.

35. Gingrich JR, Barrios RJ, Kattan MW, Nahm HS, Finegold MJ, and Greenberg NM. Androgen-independent prostate cancer progression in the TRAMP model. Cancer Res 1997; 57: 4687-4691.

36. Eng MH, Charles LG, Ross BD, Chrisp CE, Pienta KJ, Greenberg NM, Hsu CX, and Sanda MG. Early castration reduces prostatic carcinogenesis in transgenic mice. Urology 1999; 54: 1112-1119.
37. Pretlow TG, Delmoro CM, Dilley GG, Spadafora CG, and Pretlow TP. Transplantation of human prostatic carcinoma into nude mice in Matrigel. Cancer Res 1991; 51: 38143817.

38. Pretlow TG, Wolman SR, Micale MA, Pelley RJ, Kursh ED, Resnick MI, Bodner DR, Jacobberger JW, Delmoro CM, Giaconia JM and Pretlow TP. Xenografts of primary human prostatic carcinoma. J Natl Cancer Inst 1993; 85: 394-398.

39. Green DR. Apoptotic pathways: the roads to ruin. Cell 1998; 94: 695-698.

40. Shirai T, Nakamura A, Fukushima S, Yamamoto A, Tada M, and Ito N. Different carcinogenic responses in a variety of organs, including the prostate, of five different rat strains given 3,2'-dimethyl-4-aminobiphenyl. Carcinogenesis 1990; 11: $793-797$.

41. Asamoto M, Hokaiwado N, Cho Y-M, Takahashi S, Ikeda Y, Imaida K, and Shirai T. Prostate carcinomas developing in transgenic rats with SV40 $\mathrm{T}$ antigen expression under probasin promoter control are strictly androgen dependent. Cancer Res 2001; 61: 4693-4700.

42. Asamoto M, Hokaiwado N, Cho YM, and Shirai T. Effects of genetic background on prostate and taste bud carcinogenesis due to SV40 T antigen expression under probasin gene promoter control. Carcinogenesis 2002; 23: 463-467. 